\title{
Episodic Abdominal Pain Characteristics Are Not Associated with Clinically Relevant Improvement of Health Status After Cholecystectomy
}

\author{
Mark P. Lamberts ${ }^{1,2,3}$ • Wietske Kievit ${ }^{4}$. Jos J. G. M. Gerritsen ${ }^{5}$ - Jan A. Roukema ${ }^{6}$. \\ Gert P. Westert ${ }^{1}$ • Joost P. H. Drenth ${ }^{2}$ • Cornelis J. H. M. van Laarhoven ${ }^{3}$
}

Received: 6 January 2016 / Accepted: 28 March 2016 / Published online: 17 May 2016

(C) 2016 The Author(s). This article is published with open access at Springerlink.com

\begin{abstract}
Background Cholecystectomy is the therapy of first choice in patients with uncomplicated symptomatic cholecystolithiasis, but it remains unclear which patients truly benefit in terms of health status improvement. Patients generally present with episodic abdominal pain of varying frequency, duration, and intensity. We assessed whether characteristics of abdominal pain episodes are determinants of clinically relevant improvement of health status after cholecystectomy.

Methods In a post hoc analysis of a prospective multicenter cohort study, patients of $\geq 18$ years of age with uncomplicated symptomatic cholecystolithiasis subjected to cholecystectomy were included. Preoperatively, patients received a structured interview and a questionnaire consisting of the visual analogue scale (VAS; range 0-100) and gastrointestinal quality of life index (GIQLI). At 12 weeks after cholecystectomy, the GIQLI was again administered. Logistic regression analyses were performed to determine significant associations.

Results Questionnaires were sent to 261 and returned by 166 (63.6 \%) patients (128 females, mean age at surgery $49.5 \pm 13.8$ ). A total of $131(78.9 \%)$ patients reported a clinically relevant improvement of health status. The median (interquartile range) frequency, duration, and intensity of abdominal pain episodes were $0.38(0.18-0.75)$ a week, $4.00(2.00-8.00)$ hours, and 92 (77-99), respectively. None of the characteristics was associated with a clinically relevant improvement of health status at 12 weeks after cholecystectomy.

Conclusions Characteristics of abdominal pain episodes cannot be used to inform patients with symptomatic cholecystolithiasis who are skeptic about the timing of cholecystectomy for optimal benefit. Timing of cholecystectomy should therefore be based on other characteristics and preferences.
\end{abstract}

Mark P. Lamberts

Marklamberts@hotmail.com

1 Scientific Institute for Quality of Healthcare (IQ healthcare), Radboud University Medical Centre, PO Box 9101, 6500 HB Nijmegen, The Netherlands

2 Department of Gastroenterology and Hepatology, Radboud University Medical Centre, Nijmegen, The Netherlands

3 Department of Surgery, Radboud University Medical Centre, Nijmegen, The Netherlands

4 Department for Health Evidence, Radboud University Medical Centre, Nijmegen, The Netherlands

5 Department of Surgery, Medisch Spectrum Twente, Enschede, The Netherlands

6 Department of Surgery, St. Elisabeth Hospital, Tilburg, The Netherlands
Keywords Pain $\cdot$ Health status $\cdot$ Cholecystectomy

\section{Introduction}

Cholecystolithiasis represents a clinical spectrum that ranges from asymptomatic gallstone disease to uncomplicated symptomatic gallstone disease to acute cholecystitis. Likewise, therapeutic options may go from conservative treatment to cholecystectomy. Patients with asymptomatic cholecystolithiasis benefit least from cholecystectomy in terms of improvement of health status and should receive conservative care, whereas those with acute cholecystitis benefit most and should receive surgery. ${ }^{1-4}$ The optimal timing that results in the highest benefit for patients with uncomplicated symptomatic cholecystolithiasis remains less clear. 
Uncomplicated symptomatic cholecystolithiasis is frequently characterized by abdominal pain episodes of widely varying frequency. These episodes may last minutes or several hours, and their intensity is variable. ${ }^{5}$ Previous studies have shown that patients with a higher frequency of episodic abdominal pain were less likely to obtain pain relief after cholecystectomy. ${ }^{6-10}$ Conversely, those with a typical episode duration between $30 \mathrm{~min}$ and $24 \mathrm{~h}$ were more likely to report absence of pain after surgery, whereas patients with a higher pain intensity were not more likely to report absence of pain. ${ }^{10}$ Abdominal symptom characteristics may also indicate which patients are most likely to display clinically relevant improvement of patient-reported overall health status after cholecystectomy: a more comprehensive outcome measure that not only includes symptom evaluation, but also emotional, physical, and social functioning. ${ }^{11}$

We aimed to assess whether frequency, maximum duration, or intensity of abdominal pain episodes were associated with improvement of health status in order to define which patients with uncomplicated symptomatic cholecystolithiasis may benefit most from cholecystectomy. We also assessed the associations of these episode characteristics with different subscales of health status at 12 weeks after cholecystectomy.

\section{Methods}

\section{Study Sites and Patient Selection}

We performed a post hoc analysis using the database established during a previous multicenter cohort study conducted in the Netherlands. Details of study design were reported previously. ${ }^{12}$ In short, all individuals aged 18 years and over with symptomatic cholelithiasis, who visited the surgical outpatient clinic at a tertiary referral center (Radboud University Medical Centre, Nijmegen) or one of the two non-academic teaching hospitals (St. Elisabeth Hospital, Tilburg and the Medisch Spectrum Twente Hospital, Enschede) between June 2012 and June 2014, and were scheduled for elective cholecystectomy were eligible for participation in the study. Cholelithiasis was defined as abdominal pain associated with gallstones, confirmed with ultrasound imaging. Medical histories were obtained by a single physician (MPL) through a structured interview.

Patients were asked to recall the duration of symptoms, the number of episodes, and longest episode duration. Patients with a history of symptoms for more than 1 year or who reported to have experienced more than five episodes were excluded, because most of these patients could not recall the frequency. Consequently, these data were only sporadically reported in the database. In addition, we excluded those with schizophrenia or other mental disorders that may impair recall. Other exclusion criteria were as follows: a history of complicated symptomatic cholelithiasis (acute cholecystitis, cholangitis, biliary pancreatitis, choledocholithiasis requiring endoscopic retrograde cholangiopancreatography $($ ERCP $)),{ }^{13,14}$ ASA fitness grades III and IV, insufficient knowledge of the Dutch language, non-Dutch residency, blindness, pregnancy, cirrhosis, or cancer treatment. Eligible patients were asked to complete a questionnaire before cholecystectomy and 12 weeks after cholecystectomy. Patients who failed to return or complete the questionnaire before and after surgery were excluded.

The questionnaire consisted of the gastrointestinal quality of life index (GIQLI). The GIQLI has been developed in Germany and has been translated and validated in Dutch. ${ }^{15,16}$ For an example of the questions and response categories of this questionnaire, we refer to a previous study. ${ }^{15}$ The GIQLI addresses upper and lower gastrointestinal symptoms (19 questions), emotional (5 questions), physical (7 questions), social well-being (4 questions), and effect of medical treatment (1 question) in the previous 2 weeks. Each question contains five response categories. Questions can be scored using a response scale ranging from 0 (worst appraisal) to 4 points (best appraisal) for each question, giving an overall score of 0-144 points. The higher the score, the better overall health status is. A clinically relevant improvement after surgery was defined as an increase of 5 points or more in the overall score or in any of the subscales. ${ }^{17}$ We also included a visual analogue score (VAS) providing a range of scores from 0 to 100 to quantify the maximum severity of pain preoperatively.

The study was approved by the medical ethics committee and reported in accordance with the recommendations in the Strengthening the Reporting of Observational studies in Epidemiology (STROBE) guidelines for reporting observational studies. ${ }^{18}$

\section{Outcomes and Variables of Interest}

The primary outcome was defined as a clinically relevant improvement of overall health status. Secondary outcomes included a clinically relevant improvement of upper and lower gastrointestinal symptoms, or on the emotional, physical, and social subscales, respectively. Based on previous publications, the independent variables included sex, ${ }^{10,19}$ age at operation, ${ }^{10,19}$ center, ${ }^{10}$ baseline GIQLI score, ${ }^{19}$ ASA fitness grade, frequency, maximum duration, and intensity of abdominal pain episodes.

\section{Statistical Analysis}

We examined whether baseline clinical and abdominal pain characteristics differed between responders and nonresponders to the questionnaire, using $\chi^{2}$ tests or Fisher's exact tests for categorical data, Student's $t$ tests for continuous 
data, and Mann-Whitney $U$ tests for ordinal data. We determined which variables were associated in univariable analysis with a clinically relevant improvement of health status after surgery using logistic regression analyses. Significant variables in univariable analysis $(P<0.10)$ were introduced into a backward multivariable regression model to determine whether there were independent predictors of clinically relevant improvement of overall health status or any of the subscales after surgery. Age at operation, sex, center, and baseline GIQLI score were the variables that were retained in the model as co-variables. Results were reported as adjusted odds ratios (ORs) with corresponding $95 \%$ confidence intervals. $P<0.05$ was considered statistically significant. All missing values were considered to be completely at random and excluded from analyses. Statistical analyses were performed using SPSS statistical software version 20.0 (IBM, Armonk, NY, USA).

\section{Results}

The database consisted of 870 potentially eligible patients. A total of 261 patients were included. Preoperative and postoperative questionnaires were returned and completed by 166 (63.6\%) patients (Fig. 1). Baseline characteristics of the responding patients are shown in Table 1. One hundred and twenty-eight of the responding patients were females. Mean age at surgery was $49.5 \pm 13.8$ years. The median (interquartile range) frequency, duration, and intensity of abdominal pain episodes were $0.38(0.18-0.75)$ a week, $4.00(2.00-8.00)$ hours, and 92 (77-99), respectively. Baseline and abdominal pain characteristics did not differ between responders and non-responders.

One hundred and thirty-one (78.9\%) patients reported an overall clinically relevant improvement after surgery. Univariable analysis showed maximum intensity of abdominal pain episodes to be associated with clinically relevant improvement of overall health status (OR 1.02, $95 \%$ CI 1.00 1.04; $P=0.069$ ) (Table 2). Maximum intensity of abdominal pain episodes did not remain associated in multivariable analysis (OR 1.03, $95 \%$ CI 1.00-1.05; $P=0.066$ ).

On the gastrointestinal symptom subscale, 105 (63.3\%) patients reported a clinically relevant improvement (Table 3). The emotional subscale showed a clinically relevant improvement in 37 (22.3\%) patients. A clinically relevant improvement of the physical subscale was reported by 54 $(32.5 \%)$ patients. Thirty-nine $(23.5 \%)$ patients showed a clinically relevant improvement of the social subscale.

Duration was associated with clinically relevant improvement of the physical (OR 1.07, $95 \%$ CI $1.02-$ $1.12 ; P=0.007)$ and social subscales (OR 1.09, $95 \%$ CI $1.04-1.14 ; P<0.001)$ in univariable analysis (Table 3). Univariable analysis showed frequency to be associated with clinically relevant improvement of the social subscale (OR 2.39, $95 \%$ CI 1.11-5.12; $P=0.025$ ). In multivariable analysis, duration (OR $1.10,95 \% \mathrm{CI}, 1.03-1.17 ; P=0.003)$ and frequency (OR 2.95, $95 \%$ CI 1.08-8.08; $P=0.035$ ) of abdominal pain episodes with clinically relevant improvement of the social subscale remained associated.

\section{Discussion}

This study showed a clinically relevant improvement of overall health status in $131(78.9 \%)$ patients at 12 weeks after cholecystectomy. Episode characteristics of pain were not associated with an overall clinically relevant improvement of health status after surgery, but patients with a higher frequency and a longer duration of abdominal pain episodes were more likely to have a clinically relevant improvement of social functioning after surgery.

The preoperative health status score and improvement of health status were similar to studies using the same patientreported outcomes. ${ }^{1-4}$ We measured patient-reported outcomes at 12 weeks after cholecystectomy as studies suggest that the results at this time point persist at long-term followup. ${ }^{10,20}$ In studies defining clinically relevant health outcome after surgery exclusively as pain or symptom relief, abdominal pain episode characteristics were associated with a better outcome. ${ }^{6-10}$ We showed, however, that characteristics of abdominal pain episodes were not associated with overall health outcome when other factors such as emotional and social functioning are also taken into account. No associations were found between abdominal pain episode characteristics and all the subscales of health status, except for the social subscale. This study showed an association of increased pain episode frequency with the social subscale of health status improvement. In addition, a longer duration of pain episodes has been associated with absence of pain, ${ }^{10}$ whereas an association was found with clinically relevant improvement of social functioning in this study. The higher frequency and longer duration may have been caused by an undetected social disabling mild acute cholecystitis. ${ }^{13}$ This suggestion may certainly fit with the spectrum of cholecystolithiasis.

The main explanation for the discrepant results with literature is the difference in patient-reported outcomes. The most comprehensive patient-reported outcome measure in patients with uncomplicated symptomatic cholecystolithiasis to determine appropriate and efficient utilization of cholecystectomy is still under debate. Postoperative absence of pain, satisfaction, and health status improvement all have been previously used as primary patient-reported outcome measures. ${ }^{11}$ Argument for using patient-reported absence of postoperative pain as primary outcome is that the diagnosis of uncomplicated symptomatic cholecystolithiasis is based on abdominal 
Fig. 1 Flow chart showing inclusion of patients in the study

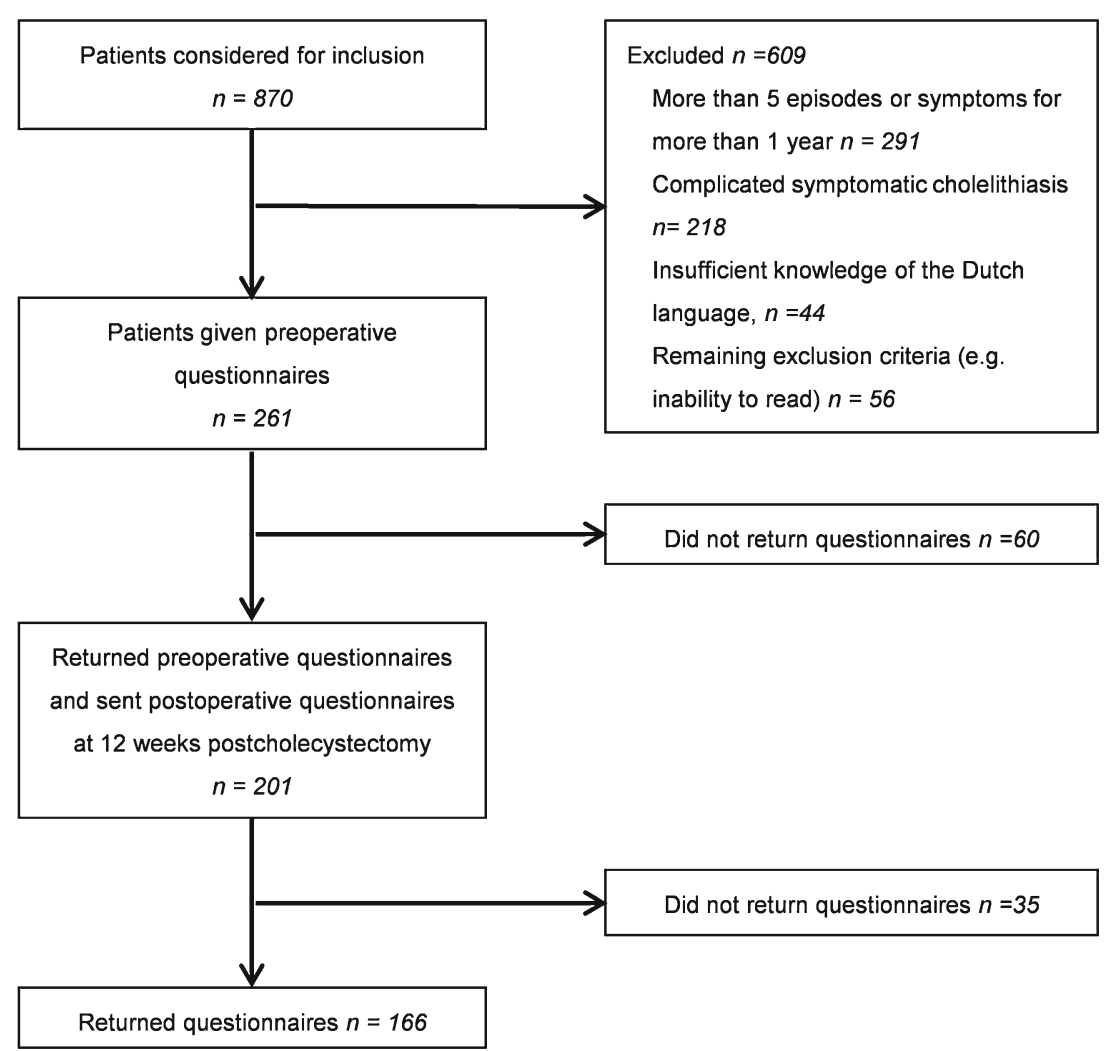

pain. ${ }^{21-23}$ In addition, postoperative pain after cholecystectomy is the main predictor of a patient-reported unsuccessful outcome. ${ }^{24}$ Satisfaction as primary outcome has the advantage of providing information about the relationship between
Table 1 Characteristics of the responding and non-responders to the questionnaires

\begin{tabular}{llll}
\hline Characteristic & Responders, $n=166$ & Non-responders, $n=95$ & $P$ value \\
\hline $\begin{array}{l}\text { Age (years) } \\
\text { Sex }\end{array}$ & $49.5 \pm 13.8$ & $46.3 \pm 16.3$ & 0.09 \\
$\quad$ Male & $38(22.9)$ & $23(24.2)$ & 0.81 \\
Female & $128(77.1)$ & $72(75.8)$ & \\
ASA fitness grade & & & 0.46 \\
I & $83(50.0)$ & $52(54.7)$ & \\
II & $83(50.0)$ & $43(45.3)$ & NA \\
Center & & & NA \\
$\quad$ Radboud UMC & $36(21.7)$ & $47(20.0)$ & NA \\
$\quad \begin{array}{l}\text { MST } \\
\text { St Elisabeth Hospital }\end{array}$ & $69(41.6)$ & $29(32.2)$ & 0.65 \\
Frequency of abdominal pain & $61(36.7)$ & $0.3(0.2-0.7)$ & 0.48 \\
$\quad$ episodes a week & $0.4(0.2-0.8)$ & $4.0(2.0-6.3)$ & NA \\
$\begin{array}{l}\text { Duration of longest abdominal } \\
\text { pain episode in hours }\end{array}$ & $4.0(2.0-8.0)$ & & NA \\
$\begin{array}{l}\text { Maximum intensity of pain } \\
\text { episode ranging 0-100 }\end{array}$ & $92(77-99)$ & & NA \\
$\begin{array}{l}\text { Baseline GIQLI score } \\
\text { GIQLI score 12 weeks after } \\
\text { cholecystectomy }\end{array}$ & $103.5 \pm 22.1$ & & \\
\hline
\end{tabular}

Data are expressed as mean (standard deviation) or $n$ (\%) or median (interquartile range)

$A S A$ American Society of Anesthesiologists, GIQLI gastrointestinal quality of life index, UMC University Medical Center, NA not applicable, MST Medisch Spectrum Twente hospital 
Table 2 Univariable and multivariable association of pain episode characteristics with patient-reported minimal clinically important improvement of health status

\begin{tabular}{|c|c|c|c|c|c|c|}
\hline & \multicolumn{2}{|c|}{ Clinically relevant improvement } & \multicolumn{2}{|l|}{ Univariable analysis } & \multicolumn{2}{|l|}{ Multivariable analysis } \\
\hline & $\begin{array}{l}<5 \text { points on GIQLI, } \\
n=35\end{array}$ & $\begin{array}{l}\geq 5 \text { points on GIQLI, } \\
n=131\end{array}$ & Odds ratio $(95 \% \mathrm{CI})$ & $P$ value & Odds ratio $(95 \% \mathrm{CI})$ & $P$ value \\
\hline Age (years) & $50.6 \pm 13.6$ & $49.2 \pm 13.9$ & $0.99(0.97-1.02)$ & 0.586 & $1.0(0.96-1.04)$ & 0.885 \\
\hline Sex & & & & 0.179 & & 0.650 \\
\hline Female & $24(68.6)$ & $104(79.4)$ & $1.77(0.77-4.05)$ & & $0.76(0.24-2.46)$ & \\
\hline Male & $11(31.4)$ & $27(20.6)$ & 1.00 (reference) & & & \\
\hline Hospital type & & & & 0.850 & & 0.812 \\
\hline Tertiary referral center & $8(22.9)$ & $28(21.4)$ & $0.92(0.38-2.24)$ & & $0.86(0.24-3.06)$ & \\
\hline Non-academic & $27(77.1)$ & $103(78.6)$ & 1.00 (reference) & & & \\
\hline Baseline GIQLI score & $126.6 \pm 11.8$ & $97.3 \pm 20.0$ & $0.88(0.84-0.92)$ & $<0.001$ & $0.88(0.84-0.92)$ & $<0.001$ \\
\hline ASA fitness grade & & & & 0.568 & & \\
\hline II & $16(45.7)$ & $67(51.1)$ & $1.24(0.59-2.63)$ & & & \\
\hline I & $19(54.3)$ & $64(48.8)$ & 1.00 (reference) & & & \\
\hline $\begin{array}{l}\text { Frequency of pain episodes } \\
\text { a week }\end{array}$ & $0.4(0.2-0.5)$ & $0.4(0.2-1.0)$ & $1.66(0.65-4.26)$ & 0.287 & & \\
\hline $\begin{array}{l}\text { Maximum duration of } \\
\text { longest pain episode in } \\
\text { hours }\end{array}$ & $4.0(2.5-9.0)$ & $4.0(2.0-8.0)$ & $1.01(0.96-1.07)$ & 0.648 & & \\
\hline $\begin{array}{l}\text { Maximum intensity of pain } \\
\text { episode ranging } 0-100\end{array}$ & $88.5(72.0-94.3)$ & $93.5(79.0-99.8)$ & $1.02(1.00-1.04)$ & 0.069 & $1.03(1.00-1.05)$ & 0.066 \\
\hline
\end{tabular}

Data are expressed as mean (standard deviation) or $n(\%)$ or median (interquartile range)

$95 \%$ CI, $95 \%$ confidence interval, ASA American Society of Anesthesiologists, GIQLI gastrointestinal quality of life index

patient expectations and the treatment experience. Satisfaction incorporates the description of healthcare from the patient's viewpoint, measurement of the process of care, and evaluation of its outcome. ${ }^{11}$ Finally, argument for using health status improvement is that it measures various domains of health and on a continuous scale. This outcome allows us to determine which patient benefits most from therapy. ${ }^{11}$ Health status improvement was therefore chosen as primary patientreported outcome in this study.

Our study has some limitations. First, we cannot fully rule out recall bias, although we limited this type of bias by excluding patients that could not recall abdominal pain frequency. The generalizability of the results may therefore be limited, although the patient characteristics are no different compared with the characteristics of other studies. ${ }^{5-10}$ Second, the inclusion of referred patients and the limited response rate may have caused selection bias, although we did not find any significant differences between the responding and nonresponding patients. Third, we performed a post hoc analysis using a database of a previous multicenter cohort study. A formal power analysis was therefore not conducted. Finally, the natural course of symptoms ${ }^{25,26}$ placebo effect of surgery, ${ }^{27}$ or expectancy of patients ${ }^{28}$ may have biased the questionnaire answers. Concerning the wax and waning of abdominal pain episodes, ${ }^{5}$ we corrected for preoperative health status. Unfortunately, randomized trials to limit biased questionnaire answers were prohibited due to ethical reasons.

This study included several strengths as well. First, the database of a prospective observational study was used limiting confounding bias. Second, we used a standardized and validated questionnaire allowing reliable comparisons with other studies using this widely translated and validated questionnaire. ${ }^{15,16}$ Third, using a single interviewer in all three centers excluded interobserver bias. Finally, patients were recruited from both tertiary and general hospitals increasing the generalizability.

Since patients that benefit most in terms of health status improvement cannot be predicted using abdominal pain episode characteristics, future studies should assess which uncomplicated symptomatic cholecystolithiasis patients are at increased risk for complicated cholecystolithiasis. Although the risk of complications because of gallstones in uncomplicated symptomatic cholecystolithiasis patients is estimated to be only $1-3 \%$ a year, these complications can be serious and life threatening as previously reported in this journal. ${ }^{29,30}$ Preventing uncomplicated symptomatic cholecystolithiasis patients to proceed to complicated symptomatic cholecystolithiasis by early cholecystectomy would increase the cost-effectiveness of this common surgical procedure.

In conclusion, frequency, maximum duration, and intensity of abdominal pain episodes are not associated with a patient- 


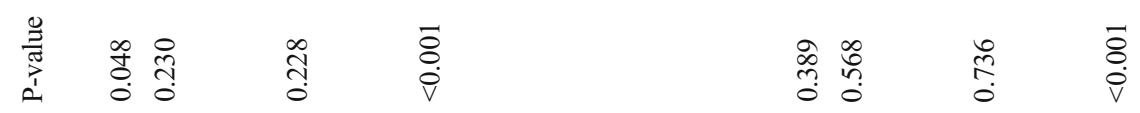

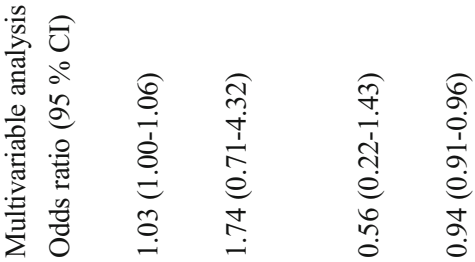

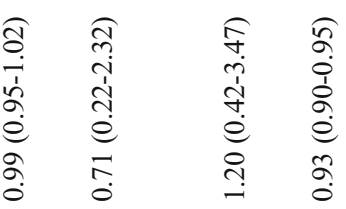

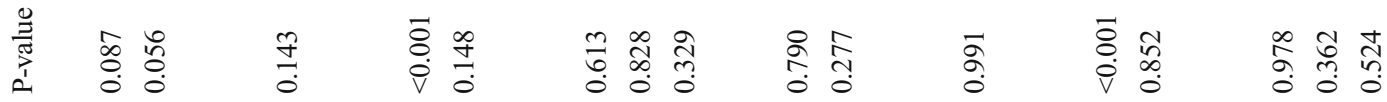

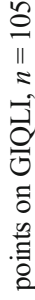

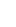

苞

है

हैं

音

造

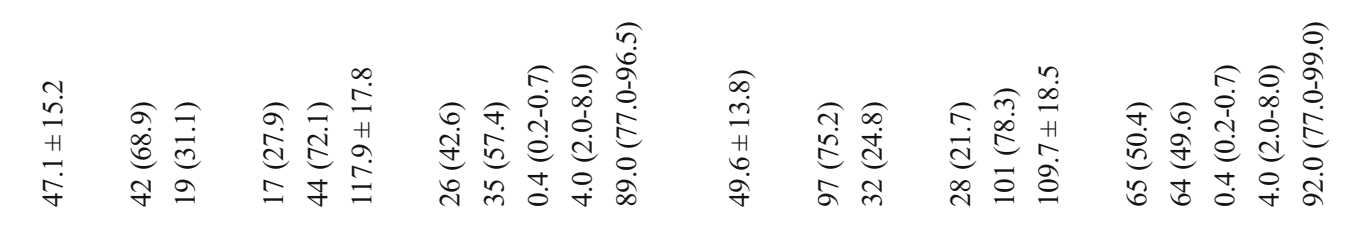

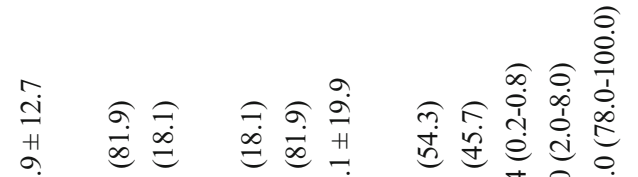

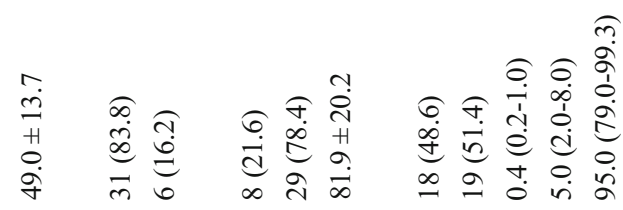
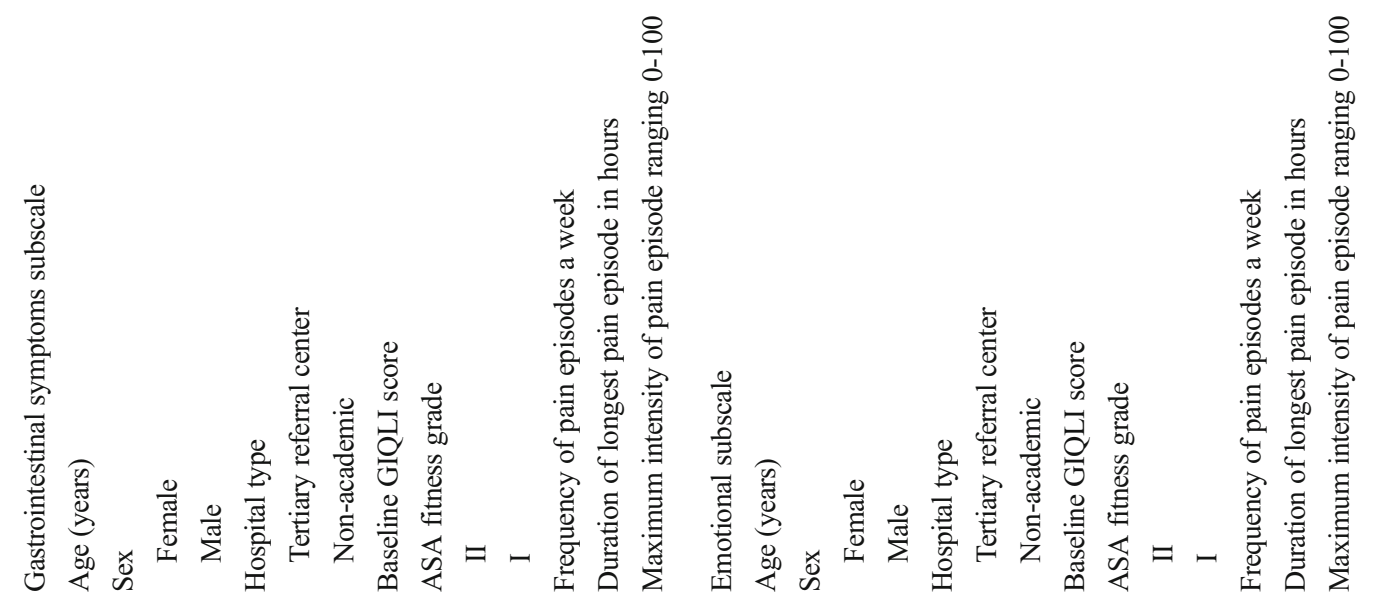


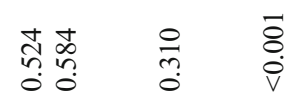

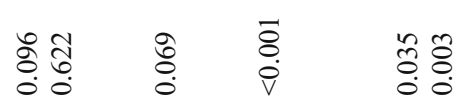

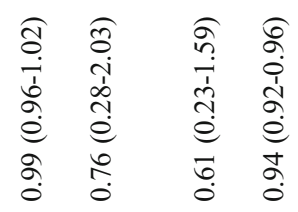

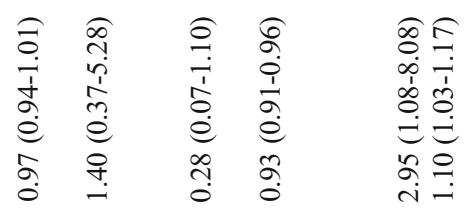

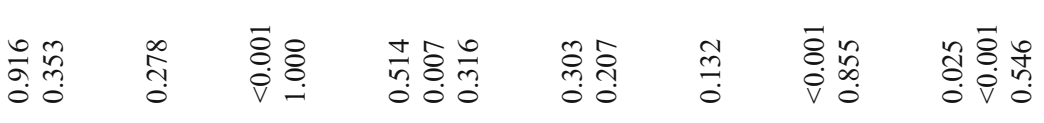

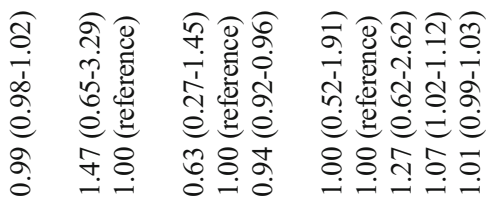

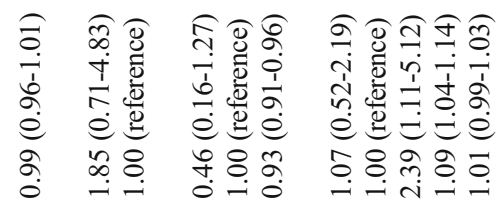

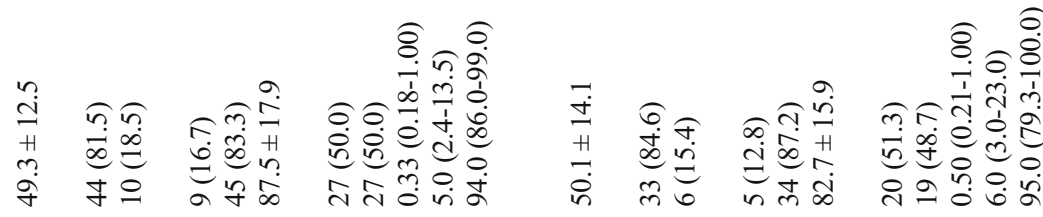

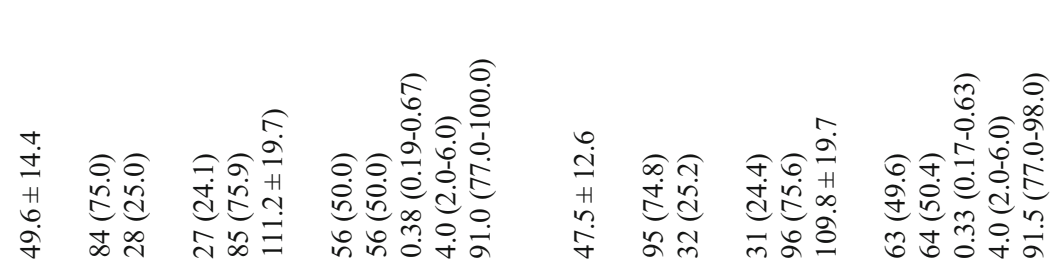
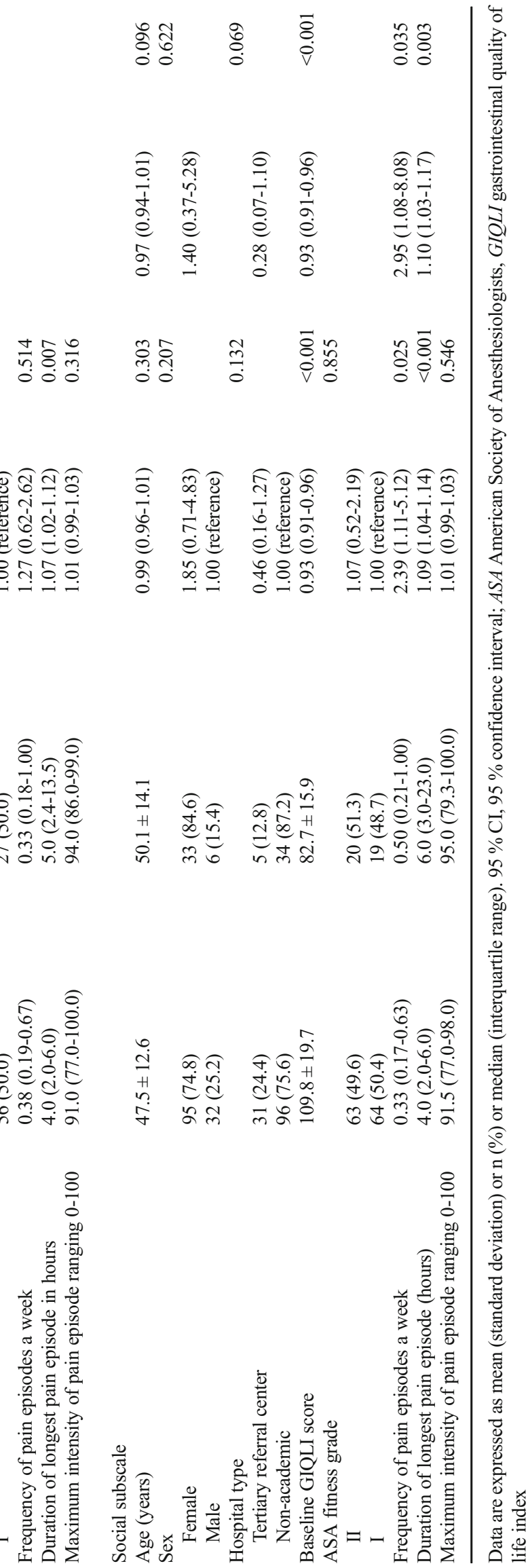
reported clinically relevant improvement of health status at 12 weeks after cholecystectomy. Characteristics of abdominal pain episodes cannot be used to inform patients with symptomatic cholecystolithiasis who are skeptic about the timing of cholecystectomy for optimal benefit. Timing of cholecystectomy for these patients should therefore be based on other characteristics and preferences.

Compliance with Ethical Standards The study was approved by the medical ethics committee and reported in accordance with the recommendations in the Strengthening the Reporting of Observational studies in Epidemiology (STROBE) guidelines for reporting observational studies. ${ }^{18}$

Conflict of Interest The authors declare that they have no conflicts of interest.

Open Access This article is distributed under the terms of the Creative Commons Attribution 4.0 International License (http:// creativecommons.org/licenses/by/4.0/), which permits unrestricted use, distribution, and reproduction in any medium, provided you give appropriate credit to the original author(s) and the source, provide a link to the Creative Commons license, and indicate if changes were made.

\section{References}

1. Lien HH, Huang CC, Wang PC, Huang CS, Chen YH, Lin TL, Tsai MC. Changes in quality-of-life following laparoscopic cholecystectomy in adult patients with cholelithiasis. J. Gastrointest. Surg. 2010;14:126-130.

2. Mentes BB, Akin M, Irkorucu O, Tatlicioglu E, Ferahkose Z, Yildinm A, Maral I. Gastrointestinal quality of life in patients with symptomatic or asymptomatic cholelithiasis before and after laparoscopic cholecystectomy. Surg. Endosc. 2001;15:1267-1272.

3. Quintana JM, Arostegui I, Cabriada J, Lopez de Tejada I, Perdigo L. Predictors of improvement in health-related quality of life in patients undergoing cholecystectomy. Br. J. Surg. 2003;90:15491555.

4. Quintana JM, Cabriada J, Arostegui I, Oribe V, Perdigo L, Varona M, Bilbao A. Health-related quality of life and appropriateness of cholecystectomy. Ann. Surg. 2005;241:110-118.

5. Berhane T, Vetrhus M, Hausken T, Olafsson S, Sondenaa K. Pain attacks in non-complicated and complicated gallstone disease have a characteristic pattern and are accompanied by dyspepsia in most patients: the results of a prospective study. Scand. J. Gastroenterol. 2006;41:93-101.

6. Blichfeldt-Eckhardt MR, Ording H, Andersen C, Licht PB, Toft P. Early visceral pain predicts chronic pain after laparoscopic cholecystectomy. Pain 2014;155:2400-7.

7. Halldestam I, Kullman E, Borch K. Defined indications for elective cholecystectomy for gallstone disease. Br. J. Surg. 2008;95:620 626.

8. Lublin M, Crawford DL, Hiatt JR, Phillips EH. Symptoms before and after laparoscopic cholecystectomy for gallstones. Am. Surg. 2004;70:863-866.

9. Schmidt M, Sondenaa K, Dumot JA, Rosenblatt S, Hausken T, Ramnefjell M, Njolstad G, Eide GE. Post-cholecystectomy symptoms were caused by persistence of a functional gastrointestinal disorder. World J. Gastroenterol. 2012;18(12):1365-1372.
10. Thistle JL, Longstreth GF, Romero Y, Arora AS, Simonson JA, Diehl NN, Harmsen WS, Zinsmeister AR. Factors that predict relief from upper abdominal pain after cholecystectomy. Clin. Gastroenterol. Hepatol. 2011;9:891-896.

11. Korolija D, Wood-Dauphinee S, Pointner R. Patient-reported outcomes. How important are they? Surg. Endosc. 2007;21:503-507.

12. Lamberts MP, Den Oudsten BL, Gerritsen JJ, Roukema JA, Westert GP, Drenth JP, van Laarhoven CJ. Prospective multicentre cohort study of patient-reported outcomes after cholecystectomy for uncomplicated symptomatic cholecystolithiasis. Br. J. Surg. 2015;102:1402-9.

13. Mayumi T, Takada T, Kawarada Y, Nimura Y, Yoshida M, Sekimoto M, Miura F, Wada K, Hirota M, Yamashita Y, Nagino M, Tsuyuguchi T, Tanaka A, Gomi H, Pitt HA. Results of the Tokyo Consensus Meeting Tokyo Guidelines. J. Hepatobiliary Pancreat. Surg. 2007;14:114-121.

14. van Santvoort HC, Besselink MG, de Vries AC, Boermeester MA, Fischer K, Bollen TL, Cirkel GA, Schaapherder AF, Nieuwenhuijs $\mathrm{VB}$, van Goor $\mathrm{H}$, Dejong $\mathrm{CH}$, van Eijck $\mathrm{CH}$, Witteman BJ, Weusten BL, van Laarhoven CJ, Wahab PJ, Tan AC, Schwartz MP, van der Harst E, Cuesta MA, Siersema PD, Gooszen HG, van Erpecum KJ, Dutch Acute Pancreatitis Study G. Early endoscopic retrograde cholangiopancreatography in predicted severe acute biliary pancreatitis: a prospective multicentre study. Ann. Surg. 2009;250:68-75.

15. Eypasch E, Williams JI, Wood-Dauphinee S, Ure BM, Schmulling C, Neugebauer E, Troidl H. Gastrointestinal Quality of Life Index: development, validation and application of a new instrument. Br. J. Surg. 1995;82:216-222.

16. Nieveen Van Dijkum EJ, Terwee CB, Oosterveld P, Van Der Meulen JH, Gouma DJ, De Haes JC. Validation of the gastrointestinal quality of life index for patients with potentially operable periampullary carcinoma. Br. J. Surg. 2000;87:110-115.

17. Shi HY, Lee HH, Chiu CC, Chiu HC, Uen YH, Lee KT. Responsiveness and minimal clinically important differences after cholecystectomy: GIQLI versus SF-36. J. Gastrointest. Surg. 2008; 12:1275-1282.

18. von Elm E, Altman DG, Egger M, Pocock SJ, Gotzsche PC, Vandenbroucke JP, Initiative S. The Strengthening the Reporting of Observational Studies in Epidemiology (STROBE) statement: guidelines for reporting observational studies. J. Clin. Epidemiol. 2008;61:344-349.

19. Quintana JM, Arostegui I, Oribe V, Lopez de Tejada I, Barrios B, Garay I. Influence of age and gender on quality-of-life outcomes after cholecystectomy. Qual. Life. Res. 2005;14:815-825.

20. Lamberts MP, Oudsten BL, Keus F, De Vries J, van Laarhoven CJ, Westert GP, Drenth JP, Roukema JA. Patient-reported outcomes of symptomatic cholelithiasis patients following cholecystectomy after at least 5 years of follow-up : A long-term prospective cohort study. Surg. Endosc. 2014;28:3443-50.

21. The epidemiology of gallstone disease in Rome, Italy. Part II. Factors associated with the disease. The Rome Group for Epidemiology and Prevention of Cholelithiasis (GREPCO). Hepatol. 1988;8:907-913.

22. The epidemiology of gallstone disease in Rome, Italy. Part I. Prevalence data in men. The Rome Group for Epidemiology and Prevention of Cholelithiasis (GREPCO). Hepatol. 1988;8:904906.

23. Berger MY, van der Velden JJ, Lijmer JG, de Kort H, Prins A, Bohnen AM. Abdominal symptoms: do they predict gallstones? A systematic review. Scand. J. Gastroenterol. 2000;35:70-76.

24. Weinert CR, Arnett D, Jacobs D, Jr., Kane RL. Relationship between persistence of abdominal symptoms and successful outcome after cholecystectomy. Arch. Intern. Med. 2000;160: 989-995. 
25. Vetrhus M, Soreide O, Eide GE, Solhaug JH, Nesvik I, Sondenaa K. Pain and quality of life in patients with symptomatic, noncomplicated gallbladder stones: results of a randomized controlled trial. Scand. J. Gastroenterol. 2004;39:270-276.

26. Vetrhus M, Soreide O, Solhaug JH, Nesvik I, Sondenaa K. Symptomatic, non-complicated gallbladder stone disease. Operation or observation? A randomized clinical study. Scand. J. Gastroenterol. 2002;37:834-839.

27. Finniss DG, Kaptchuk TJ, Miller F, Benedetti F. Biological, clinical, and ethical advances of placebo effects. Lancet 2010;375:686-695.
28. Jones KR, Burney RE, Christy B. Patient expectations for surgery: are they being met? Jt. Comm. J. Qual. Improv. 2000;26:349-360.

29. Besselink MG, Venneman NG, Go PM, Broeders IA, Siersema PD, Gooszen HG, van Erpecum KJ. Is complicated gallstone disease preceded by biliary colic? J. Gastrointest. Surg. 2009;13:312-317.

30. Friedman GD. Natural history of asymptomatic and symptomatic gallstones. Am. J. Surg. 1993;165:399-404. 